\title{
Central role of echocardiography in the diagnosis and assessment of heart failure
}

\author{
M G Cheesman, G Leech, J Chambers, M J Monaghan, P Nihoyannopoulos, for the \\ British Society of Echocardiography
}

Heart failure is a common condition that is becoming more prevalent. ${ }^{12}$ It could be defined as the inability of the heart to deliver a satisfactory output at normal filling pressures. It is a complex clinical syndrome, usually marked by progressive breathlessness on effort, and often including systemic venous congestion with resulting oedema and hepatic congestion. Clinical heart failure has a poor prognosis, ${ }^{3}$ and consumes very large amounts of health care resources. There are widespread inaccuracies in diagnosis when clinical methods alone are used, and many patients in whom the diagnosis is made in primary care prove not to have the condition on further investigation. ${ }^{4-6}$ There is some evidence of increased use of echocardiography in heart failure in UK hospitals. ${ }^{7}$

It has become clear from recent studies that pharmacological interventions significantly improve outcomes in clinical heart failure due to left ventricular (LV) systolic dysfunction, in asymptomatic LV dysfunction, and following myocardial infarction. ${ }^{8-11}$ Echocardiography is a non-invasive technique well suited to the evaluation of LV function, and most echocardiographic departments find that estimation of $\mathrm{LV}$ function occupies an increasing proportion of their workload.

Community studies of LV systolic dysfunction by echocardiography suggest a prevalence of $1.5-1.8 \%$ in symptomatic patients aged 25-74 years, depending on whether an ejection fraction of 0.3 or 0.35 was used as the criterion, with many more than that being asymptomatic. ${ }^{12}$

\section{Who should have echocardiography?}

Almost all patients with symptoms or signs of heart failure, including those postmyocardial infarction, should have an echocardiographic evaluation as early as possible in their clinical course (table 1). ${ }^{4}$ There may be a few patients in whom, because of frailty or other complex pathology, the investigation would add little to management. However, many drugs (such as angiotensin converting enzyme (ACE) inhibitors, digoxin, and potent diuretics) used in the treatment of heart failure can have serious consequences when inappropriately used-for example, in patients with severe valve stenoses. Current costs of ACE inhibitor treatment are at least $£ 100$ per year per patient. Breathlessness is frequently multifactorial, especially in elderly patients, and echocardiography is often helpful in identifying the contribution of the heart to the total symptom load.
Table 1 Who should have echocardiography?

Almost all patients with symptoms or signs of heart failure Echocardiography is more accurate than clinical judgment combined with chest $x$ rays

Left ventricular systolic function may be found to be worse than expected from clinical and chest radiological parameters. Conversely, in some patients LV contraction at rest is shown to be unexpectedly good, ${ }^{13}$ prompting a search for evidence of diastolic dysfunction or reconsideration of the diagnosis.

What echocardiographic imaging data should be collected?

The heart should be imaged from parasternal and apical "windows" routinely; if no satisfactory images can be obtained a subcostal view often helps. Cross sectional images should be recorded onto videotape. Reliance on $\mathrm{M}$ mode imaging or frozen cross sectional images alone is unsatisfactory.

LEFT VENTRICULAR GLOBAL SYSTOLIC FUNCTION If acceptable parasternal views can be obtained, it is useful to record LV chamber dimensions routinely and to measure wall thickness (table 2). In ischaemic heart disease, where wall motion abnormalities may be present, it is not satisfactory to use $M$ mode estimations of ejection fraction. Major wall motion abnormalities should be noted. Image acuity can be variable from any "window", and it is important to be honest about the accuracy of data obtained, as treatment decisions may be based on them. Provided visualisation of endocardium from apical views is good, it is useful to calculate ejection fraction (EF), using any of the well established methods. ${ }^{14}$ If there are major wall motion abnormalities, measurements of EF should be made in both four chamber and two chamber views. ${ }^{15}$ If LV function is clearly normal, there is little point in calculating EF. EF measurements should not be made if visualisation of the endocardium is insufficient; it is better then to describe global ventricular systolic function in more general terms. EF measurements made with echocardiography have been compared to angiographic and isotope methods, and it is clear that there is no ideal method fot taking this measurement. ${ }^{16}{ }^{17}$ However, prognostic information after myocardial infarction can be 
Table 2 What types of data should be collected?

Quantitation of global left ventricular function and size Description of regional wall motion

Echo and Doppler assessment of valve function

Description of right ventricular function

obtained from such measurements. ${ }^{18} \mathrm{LV}$ end systolic volume is also of prognostic importance and should be routinely recorded where possible. ${ }^{19}{ }^{20}$ Wall motion scores have been shown to correlate acceptably with measurements of EF, and can be employed when it is not possible to visualise the endocardium in one viewing plane; they were used as a major end point in the TRACE (trandolopril cardiac evaluation) study. ${ }^{21}$

There is continuing controversy as to whether measurements of EF should be made, or whether rough "eyeball" estimates of LV global systolic function should be reported instead. Clinicians usually want this information on which to base treatment decisions, but need to realise the limitations of $\mathrm{EF}$ measurement, by whatever method, and not base treatment decisions purely on numbers. Conversely, echocardiographers need to be aware of clinician's needs for information, and to be as accurate as possible. Inexperienced operators tend to underestimate ventricular volumes. Audit of interobserver variability and reproducibility should be a routine part of a department's activity. There is good evidence that these measurements can be made with a very acceptable degree of accuracy. Interobserver variation is generally greater than intraobserver variation. ${ }^{22}$

\section{LEFT VENTRICULAR REGIONAL SYSTOLIC FUNCTION}

Major wall motion abnormalities seen should always be described. Formal wall motion scores are often useful where measured, although they are most frequently used as research measures. Recommendations have been published for recording these findings. ${ }^{23}$

RIGHT VENTRICULAR SIZE AND FUNCTION

Right ventricular size and function are usually described qualitatively. Normal ranges for right ventricular dimensions have been published. ${ }^{24}$

VALVE FUNCTION

An assessment of the patient's valvular function should be undertaken by a mixture of imaging and Doppler ultrasound. Valves should be inspected in all available views. Abnormal valves should be assessed by continuous wave Doppler. Aortic valves should be assessed, if abnormal, to determine peak and mean pressure gradients and valve area. ${ }^{25-27}$ Mitral valve area can be estimated from the rate of diastolic pressure decline. ${ }^{28}{ }^{29}$ Mitral stenosis may be further evaluated by direct planimetry of the valve area from the short axis view. It is important to appreciate that valve gradients will not reflect the severity of stenosis in patients with low cardiac output. In such situations, it is better to calculate effective valve area using the "continuity equation". ${ }^{26}$ Doppler ultrasound is extremely sensitive for the detection of regurgitant lesions. Clinically unsuspected mitral and aortic regurgitant jets are frequently seen and may be readily detected using colour flow mapping or spectral Doppler. Small jets with low intensity on continuous wave evaluation are unlikely to represent clinically significant disease. A broad jet penetrating deeply into the receiving chamber combined with an intense continuous wave Doppler signal is likely to indicate a haemodynamically significant regurgitant lesion. Mitral regurgitation is very frequently seen in patients with dilated ventricles, and is often more extensive than can be appreciated by auscultation alone.

\section{PULMONARY ARTERY PRESSURE}

Pulmonary artery pressure can also often be estimated, if patients have enough tricuspid regurgitation to provide a complete flow/ velocity "envelope". 3031

LEFT VENTRICULAR DIASTOLIC FUNCTION

There is emerging literature about the ability of cross sectional imaging and pulsed Doppler to appraise LV diastolic function. ${ }^{32}$ These measurements are of great interest, but few of them are sufficiently advanced for routine use. In particular, the familiar E/A ratio rises with age $^{33} 34$ and provides insufficient data from which to draw conclusions about LV global diastolic function. A short early deceleration time, however, is associated with a poorer prognosis, and adds additional prognostic information to that provided by measurements of systolic function. ${ }^{35}$ This is an area of rapid development; new methods, such as analysis of LV filling propagation, also look promising. ${ }^{36}$

\section{How much data should be collected routinely?}

A minimum dataset should be recorded routinely. Other measures that are sometimes useful, according to availability of time and the clinical situation, are shown in table 3 .

\section{Accuracy and reliability of echocardiographic data}

Echocardiography is now established as an accurate and reproducible technique. There is no room for complacency, however, and regular audit of standards should be an essential part of every unit's activity. The British Society of Echocardiography has published guidelines for training and accreditation in echocardiography for all staff (whether technicians or medically qualified) who perform or report echocardiographic examinations. ${ }^{37}$ It is important that staff training is adequately funded and that training and audit measures are integrated into each unit's programme.

\section{How may echocardiographic findings guide management?}

IDENTIFICATION OF POOR GLOBAL SYSTOLIC FUNCTION

Clinical data alone can predict ACE inhibitor benefit in severe heart failure ${ }^{8}$ and after myocardial infarction, ${ }^{10}$ but clinical and chest $x$ ray findings underestimate the prevalence of 
Table 3 How much data should be collected routinely?

\begin{tabular}{|c|c|c|}
\hline Minimum dataset & Often also helpful & Sometimes applicable \\
\hline \multicolumn{3}{|l|}{ Left ventricle } \\
\hline \multicolumn{3}{|l|}{$M$ mode } \\
\hline $\begin{array}{l}\text { LV chamber dimension at the } \\
\text { level of the mitral leaflet tips }\end{array}$ & $\begin{array}{l}\text { Calculation of fractional } \\
\text { shortening }\end{array}$ & \\
\hline $\begin{array}{l}\text { Thickness of septum and } \\
\text { posterior wall }\end{array}$ & & Calculation of LV mass \\
\hline \multicolumn{3}{|l|}{ Cross sectional } \\
\hline $\begin{array}{l}\text { EF where possible, otherwise a } \\
\text { qualitative description of LV } \\
\text { systolic function }\end{array}$ & $\begin{array}{l}\text { Cardiac output measurement } \\
\text { by Doppler (or stroke } \\
\text { distance) }\end{array}$ & $\begin{array}{l}\text { Estimation of } \mathrm{LV} \mathrm{dP} / \mathrm{dt}_{\max } \\
\text { from the mitral } \\
\text { regurgitant Doppler signal }\end{array}$ \\
\hline \multirow{2}{*}{$\begin{array}{l}\text { Description of major wall } \\
\text { motion abnormalities }\end{array}$} & Wall motion score & \\
\hline & $\begin{array}{l}\text { If LV function appears normal, } \\
\text { a measurement of mitral valve } \\
\text { and pulmonary vein inflow } \\
\text { parameters may be useful }\end{array}$ & \\
\hline \multicolumn{3}{|l|}{$\begin{array}{l}\text { Inspections of aortic, mitral and } \\
\text { triscupid valves } \\
\text { Colour flow search for } \\
\text { regurgitant lesions }\end{array}$} \\
\hline $\begin{array}{l}\text { Continuous wave estimation of } \\
\text { valve gradients if valve appears } \\
\text { abnormal }\end{array}$ & $\begin{array}{l}\text { Continuity equation to assess } \\
\text { AV area if output low and valve } \\
\text { appears calcified }\end{array}$ & \\
\hline \multicolumn{3}{|l|}{ Right ventricle } \\
\hline $\begin{array}{l}\text { Qualitative description of right } \\
\text { ventricular size and function }\end{array}$ & $\begin{array}{l}\text { Estimation of PA end diastolic } \\
\text { pressure from pulmonary } \\
\text { regurgitant velocity and the } \\
\text { behaviour of the IVC }\end{array}$ & $\begin{array}{l}\mathrm{RV} \text { dimension } \\
\text { measurements }\end{array}$ \\
\hline \multicolumn{3}{|l|}{$\begin{array}{l}\text { Recording of tricuspid regurgitant } \\
\text { velocity when possible and } \\
\text { estimation of RV systolic } \\
\text { pressure }\end{array}$} \\
\hline $\begin{array}{l}\text { Estimation of RA pressure from } \\
\text { IVC parameters }\end{array}$ & & \\
\hline
\end{tabular}

$\mathrm{AV}$, atrioventricular; $\mathrm{EF}$, ejection fraction; IVC, inferior vena cava; LV, left ventricule; PA, pulmonary artery; RA, right atrium; RV, right ventricule.

LV dysfunction. The studies of left ventricular dysfunction (SOLVD) ${ }^{9}$ and survival and ventricular enlargement (SAVE) ${ }^{11}$ trials demonstrated significant reductions in mortality and other end points when patients with poor LV function were treated with ACE inhibitors. Thresholds of $0.35-0.4$ for EF, measured by gated radionuclide ventriculography, were used in these studies. Caution is appropriate in extrapolating these findings to echocardiographic measurements, but it has to be recognised that the only measurements of LV systolic function available to the majority of UK patients will be echocardiographic. Given caution and professional practice on the part of echo departments, it is reasonable to use echocardiographic data in this way (table 4). Clinicians need to take a global view of patients, and be aware of their local department's accuracy.

IDENTIFICATION OF ISOLATED DIASTOLIC DYSFUNCTION

It has been recognised for more than 10 years that some patients with the clinical syndrome of heart failure appear to have well preserved systolic function on echocardiography, although there is not universal agreement as to the frequency of this finding. ${ }^{38-40}$ These patients should be evaluated with great care. Diastolic function should be assessed and the diagnosis should not be immediately dismissed. The optimum treatment for these patients is still a matter of dispute. Pericardial disease should also be considered in the differential diagnosis in these patients. Respiratory variation in mitral and tricuspid inflow patterns, with a
Table 4 How may echocardiography guide management?

The identification of poor systolic function with a view to treatment with ACE inhibitors

The identification of the subgroup with predominantly diastolic dysfunction, or those with predominantly right ventricular dysfunction

The identification and assessment of valve disease

Assistance with decisions about embolic risk

short deceleration time, may be helpful in the differentiation from restrictive myocardial disease, as may tissue Doppler imaging. ${ }^{41}$

\section{IDENTIFICATION OF ISOLATED RIGHT HEART}

FAILURE

Some patients will be found to have isolated right heart failure, with normal left heart function. Identification of this subgroup is important. Treatment should be directed to the cause, such as thromboembolic disease, or the alleviation of chronic hypoxia. There is no evidence that such patients benefit significantly from ACE inhibitor therapy.

VALVE DISEASE

Significant valvular disease is sometimes missed clinically, particularly mitral stenosis. Aortic stenosis is not always easy to grade accurately in the elderly, but sizeable gradients usually preclude the use of ACE inhibitors. Regurgitant lesions may be underestimated or missed clinically, but clearly demonstration of their presence and severity may lead to more vigorous afterload reduction or consideration of valve replacement. Criteria for the latter have recently been reviewed. ${ }^{42}$ Occasionally large pericardial effusions, intracardiac masses, or intracardiac shunts are found.

EMBOLIC RISK

Assessment of embolic risk in patients with heart failure, and the resulting consideration of warfarin therapy, may be assisted by echocardiography. Embolic risk can be assessed by a combination of clinical variables and echocardiographic features. Intracardiac thrombi, a large left atrium, poor left LV function and increased LV chamber size, and mitral stenosis have all been associated with increased risk. ${ }^{43-49}$ This information has to be considered alongside the risk posed by anticoagulation to the (often quite elderly) patient. Electrical cardioversion may be attempted. Poor LV function, a very dilated atrium, or severe valve lesions usually indicate that the chance of success is less, and risk of recurrence of atrial fibrillation afterwards is higher. ${ }^{50}$

\section{New developments in echocardiography} potentially applicable to heart failure Automated wall detection algorithms ${ }^{51}{ }^{52}$ can be used to record rate of change of volume in a graphical way, similar to gated radionuclide ventriculography, and hence aim to provide more precise measurement of EF measurement; they also allow determination of additional diastolic parameters. These methods only work satisfactorily on very good quality images. 
Transoesophageal echocardiography obtains excellent pictures, even in subjects whose transthoracic images may be uninterpretable. It visualises posterior structures such as the left atrial appendage, which cannot normally be seen on routine recordings. Transoesophageal echocardiography should be considered if left atrial masses, bacterial endocarditis, or clots are suspected. However, it is more complex and "semi-invasive" than transthoracic echocardiography, and cannot be considered a routine investigation in heart failure at this time.

Dobutamine stress echocardiography shows promise in the "unmasking" of stunned or hibernating myocardium in patients with ischaemic heart disease. ${ }^{53}$ Apparently infarcted regions which transiently recover function with low dose dobutamine are likely to recover permanently after coronary revascularisation. ${ }^{54}$ It is most useful, therefore, in patients who might actually undergo revascularisation if such a hypokinetic area can be seen to recover with inotropes.

Doppler tissue imaging and colour kinesis are new technologies which encode movement of the myocardium or endocardium in colour, thus demonstrating hypokinetic, akinetic, or dyskinetic segments of cardiac wall. ${ }^{55}{ }^{56} \mathrm{Re}-$ gional myocardial thickening and ventricular synchrony are readily apparent, and chamber volume measurements may be more accurately defined. Calculation of myocardial velocity gradients is more sensitive than measuring endocardial excursion alone..$^{57-59}$ The addition of myocardial contrast agents and second harmonic imaging ${ }^{59}$ and concurrent use of dobutamine stress $^{60}$ are likely to make these clinically useful technologies.

Three dimensional reconstruction of cardiac chambers and valves shows great promise in the provision of additional information. This is an emerging technology, and the hardware requirements are currently considerable. Chamber dimensions can be estimated with greater accuracy than is possible using cross sectional methods. ${ }^{61}$ Valves can be seen and assessed with great accuracy. ${ }^{62}$

\section{Conclusion}

Although these technological advances are exciting, the priority is to apply current knowledge well, with increased use of transthoracic echocardiographic imaging in the syndrome of congestive cardiac failure. Possibly in no other condition with such a high mortality is such infrequent use made of diagnostic imaging. It is our belief that application of cross sectional imaging with Doppler ultrasound enhancement should be widespread in the evaluation of patients with this very common but highly lethal condition.

1 McMurray JM, McDonagh T, Morrison CE, et al. Trends in hospitalisation for heart failure in Scotland. Eur Heart $\mathcal{f}$ 1993;14:1158-62.

2 Reitsma JB, Mosterd A, de Craen AJM, et al. Increase in hospital admission rates for heart failure in the Netherlands, 1980-1993. Heart 1996;76:388-92.

3 Ho KKL, Anderson KM, Kannel WB, et al. Survival after the onset of congestive heart failure in the Framingham the onset of congestive heart failure in the
study subjects. Circulation 1993;88:107-15.

4 Colquhoun MC, Waine C, Monaghan MJ, et al. Investigation in general practice of patients with suspected heart failure [editorial]. Heart 1995;74:335-6.
5 Wheeldon NM, MacDonald TM, Flucker CJ, et al. Echocardiography in chronic heart failure in the community. Quart $\mathcal{F}$ Med 1993;86:17-23.

6 Remes J, Miettinen H, Reunanen A, et al. Validity of clinical diagnosis of heart failure in primary health care. Eur Heart 1991;12:315-21.

7 Hillis GS, Al-Mohammad A, Wood M, et al. Changing patterns of investigation and treatment of cardiac failure in hospital. Heart 1996:76:427-9.

8 The CONSENSUS Trial Study Group. Effects of enalapril on mortality in severe congestive heart failure: results of the
co-operative north Scandinavian enalapril study (CONSENSUS). N Engl f Med 1987;316:1429-35.

9 The SOLVD Investigators. Effects of enalapril on survival in patients with reduced left ventricular ejection fractions and
congestive cardiac failure. $N$ Engl F Med 1991;325:293302 .

10 Acute Infarction Ramipril Efficacy (AIRE) Study Investigaors. Effect of ramipril on mortality and morbidity on survival in acute myocardial infarction with clinical evidence of heart failure. Lancet 1993;342:821-8.

11 Pfeffer M, Braunwald E, Move L, et al. Effect of captopril on mortality and morbidity in patients with left ventricular dysfunction after myocardial infarction. Results of the survival and ventricular enlargement study. $N$ Engl $f \mathrm{Med}$ 1992;327:669-77.

12 McDonagh T, Morrison CE, McMurray JJ, et al. Global left ventricular systolic dysfunction in north Glasgow [abstract]. F Am Coll Cardiol 1996;27:106A

13 Soufer R, Wohlgelernter D, Vita NA, et al. Intact systolic left ventricular function in clinical congestive heart failure. $\mathrm{Am}$ 7 Cardiol 1985;55:1032-6.

14 Schiller NB, Shah PM, Crawford M, et al. Recommendations for quantitation of the left ventricle by twodimensional echocardiography. American Society of Echocardiography committee on standards, subcommittee on cardiography committee on standards, subcommittee on quantitation of two-dimensional
Soc Echocardiogr 1989;2:358-67.

15 Schiller NB, Acquatella H, Ports TA, et al. Left ventricular volume from paired biplane two-dimensional echocardiography. Circulation 1979;60:547-55.

16 Folland ED, Parisi AF, Moynihan PF, et al. Assessment of left ventricular function and volumes by real-time, two-dimensional echocardiography. A comparison of cineangiographic and radionuclide techniques. Circulation 1979;60:760-6.

17 Starling MR, Crawford MH, Sorensen SG, et al. Comparative accuracy of apical biplane cross-sectional echocardiography and gated equilibrium radionuclide angiography for estimating left ventricular size and performance. Circulation 1981;63:1075-84

18 Volpi A, De Vita C, Franzioni MG, et al. Determinants of 6-month mortality in survivors of myocardial infarction after thrombolysis. Results of the gruppo Italiano per lo studio della sopravivenza nell'infarto miocardico (GISSI-2) data base. Circulation 1993;88:416-29.

19 White HD, Norris RM, Brown MA, et al. Left ventricular end-systolic volume as the major determinant of survival after recovery from myocardial infarction. Circulation 1987; $76 ; 44-51$.

20 St John Sutton M, Pfeffer MA, Plappert T, et al. Quantitative two-dimensional echocardiographic measurements are major predictors of adverse cardiovascular events after acute myocardial infarction. The protective effects of captopril. Circulation 1994;89:68-75.

21 TRACE Study Group. The trandolopril cardiac evaluation (TRACE) study: rationale, design, and baseline characteristics of the screened population. Am 7 Cardiol 73:44C$50 \mathrm{C}$.

22 Otterstad JE, Froeland G, St John Sutton M, et al. Accuracy and reproducibility of biplane two-dimensional echocardiographic measurements of left ventricular dimensions and function. Eur Heart $\mathcal{F}$ 1997; 18:507-13.

23 Henry WL, DeMaria A, Feigenbaum $\mathrm{H}$, et al. Report on the American Society of Echocardiography committee on nomenclature and standards: identification of myocardial wall segments. American Society of Echocardiography, 1982.

24 Foale R, Nihoyannopaulos P, McKenna W, et al. Echocardiographic measurement of the normal right ventricle. $\mathrm{Br}$ Heart $\mathcal{F} 1986: 56 ; 33-44$.

25 Hatle L, Angelsen B. Pulsed and continuous wave Doppler in diagnosis and assessment of various heart lesions. In: Hatle L, Angelsen B, eds. Doppler ultrasound in cardiology: physical principles and clinical applications. Philadelphia: Lea physical principles and clinical

26 Otto CM, Pearlman AS, Comess KA, et al. Determination of the stenotic aortic valve area using Doppler echocardioof the stenotic aortic valve area using Dop
graphy. $\mathrm{F} \mathrm{Am} \mathrm{Coll} \mathrm{Cardiol} \mathrm{1986;7:509-17.}$

27 Zhang Y, Mahye E, Nitter-Hauge S. Non-invasive quantifications of the aortic valve area in aortic stenosis by Doppler echocardiography. Eur Heart f 1985;6:992-8.

28 Holen J, Aaslid R, Landmark K, et al. Determination of effective orifice area in mitral stenosis from non-invasive ultrasound Doppler data and mitral flow rate. Acta Med Scand 1977;201:83-8.

29 Kalmanson D, Veyrat C, Bouchereine F, et al. Non-invasive recording of mitral valve flow velocity patterns using pulsed Doppler echocardiography. Application to diagnosis and evaluation of mitral valve disease. Br Heart f 1977;39:51728.

30 Yock PG, Popp RL. Non-invasive estimation of right ventricular systolic pressure by Doppler ultrasound in
patients with tricuspid regurgitation. Circulation 1984;70: 657-62. 
31 Skjaerpe T, Hatle L. Non-invasive estimation of pulmonary artery pressure by Doppler ultrasound in tricuspid regurgitation. In: Spencer E, ed. Cardiac Doppler diagnosis. Boston: Martinus $\mathrm{N}$

32 Yamamoto K, Redfield MM, Nishimura RA. Analysis of left ventricular diastolic function. Heart 1996;75(suppl 2):2735.

33 Klein AL, Burstow DJ, Tajik AJ, et al. Effects of age on left ventricular dimensions and filling dynamics in 117 norma persons. Mayo Clin Proc 1994;69:212-24.

34 Miyatake K, Okamoto M, Kinoshita N, et al. Augmentation of atrial contribution to left ventricular inflow with aging as
assessed by intracardiac Doppler flowmetry. Am f Cardiol 1984;53;586-9.

35 Giannuzzi P, Temporelli PL, Bosimini E, et al. Independent and incremental prognostic value of Doppler-derived mitral deceleration time of early filling in both symptomatic and asymptomatic patients with left ventricular dysfunction. F Am Coll Cardiol 1996;28:383-90.

36 Takatsuji H, Mikami T, Urasawa K, et al. A new method for evaluation of left ventricular diastolic function: spatial and temporal analysis of left ventricular filling flow propagation by color M-mode Doppl
Cardiol 1996;27:365-71.

37 British Society of Echocardiography education and training subcommittee: training in echocardiography. Br Heart $\mathscr{F}$ 1994;71(suppl):2-5

38 Dougherty AH, Naccarelli GV, Gray EL, et al. Congestive heart failure with normal systolic function. Am f Cardio 1984;54:778-82.

39 Soufer R, Wohlgelernter D, Vita NA, et al. Intact systolic left ventricular function in congestive cardiac failure. $A m \mathcal{F}$ Cardiol 1985;55:1032-6.

40 Aguirre FV, Pearson AC, Lewen MK, et al. Usefulness of Doppler echocardiography in the diagnosis of heart failure. Am f Cardiol 1989;63:1098-102.

41 Garcia MJ, Rodriguez L, Ares M, et al. Differentiation of constrictive pericarditis from restrictive cardiomyopathy: constrictive pericarditis from restrictive cardiomyopathy: dinal axis by Doppler tissue imaging. $f \mathrm{Am}$ Coll Cardiol dinal axis by Dopp

42 Ross J. The timing of surgery for severe mitral regurgitation [editorial]. N Engl f Med 1996;335:1412-16.

43 Petersen P, Boysen G, Godtfredsen J, et al. Placebocontrolled, randomised trial of warfarin and aspirin for the prevention of thromboembolic complications in chronic atrial fibrillation: the Copenhagen AFASAK study. Lancet 1989;i:175-9.

44 Boston Area Anticoagulation Trial for Atrial Fibrillation Investigators. The effect of low-dose warfarin on the risk of
stroke in patients with non-rheumatic atrial fibrillation. $N$ Engl f Med 1990;323:1505-11.

45 EAFT (European Atrial Fibrillation Trial) Study Group. Secondary prevention in non-rheumatic atrial fibrillation after transient ischaemic attack or minor stroke. Lancet 1993;342:1406-12.

46 Stroke Prevention in Atrial Fibrillation Investigators. Predictors of thromboembolism in atrial fibrillation. I: clinical feators of thromboembolism in atrial fibrillation. I: clinical

47 Stroke Prevention in Atrial Fibrillation Investigators. Predictors of thromboembolism in atrial fibrillation. II: echocardiographic features of patients at risk. Ann Intern Med 1992;116:6-12.

48 Gottdiener JS, Van Voorhees L, Gay J, et al. Incidence and embolic potential of left ventricular thrombus in cardiomyopathy: assessment by two-dimensional echocardiography. Am $\mathcal{F}$ Cardiol 1983;52:1281-5.

49 Jugdutt BI, Sivaram CA, Wortman C. Prospective twodimensional echocardiographic evaluation of left ventricular thrombus and embolism after acute myocardial infarction. 7 Am Coll Cardiol 1989;13:554-64.
50 Dethy M, Chassat C, Roz D, et al. Doppler echocardiographic predictors of recurrence of atrial fibrillation after graphic predictors of recurrence of atrial fi
cardioversion. Am $\mathcal{F}$ Cardiol 1988;62:723-6.

51 Perez JE, Waggoner AD, Barzilai B, et al. On-line assessment of left ventricular function by automated boundary detection and ultrasonic backscatter imaging. $\mathcal{F}$ Am Coll Cardiol 1992;19:313-20.

52 Stewart W, Gunawardena S, Rodkey S, et al. Left ventricular volume calculation using integrated backscatter from echocardiography: comparison with MRI and off-line echo analysis. I Am Soc Echocardiogr 1993;6:553-63.

53 Peirard LA, De Landshere CM, Berthe C, et al. Identification of viable myocardium by echocardiography during dobutamine infusion in patients with myocardial infarction after thrombolytic therapy: comparison with positron emission tomography. 7 Am Coll Cardiol 1990;15:1021-31.

54 Perrone-Filardi P, Pace L, Prastato M, et al. Dobutamine echocardiography predicts improvement in hypoperfused dysfunctional myocardium after revascularisation in patients with $2556-65$.

55 Sutherland GR, Steward MJ, Grounstroem KWE, et al. Colour Doppler myocardial imaging: a new technique for the assessment of myocardial function. $7 \mathrm{Am}$ Soc Echocardiogr 1994;7:444-58.

56 Miyatake K, Yamagishi M, Tanaka N, et al. A new method for the evaluation of left ventricular wall motion by color-encoded tissue Doppler imaging: in vitro and in vivo studies. F Am Coll Cardiol 1995;25:717-24.

57 Sutherland GR, Caso P, Palka P, et al. Doppler myocardial imaging assessment of left ventricular volume and area: a comparison with grey scale imaging [abstract]. Eur Heart $\mathcal{F}$ 1995;16(suppl):392.

58 Fleming AD, Xia X, MacDicken WN, et al. Myocardial velocity gradient by Doppler imaging. Br F Radiol 1994;67: 679-88.

59 Sutherland GR, von Bibra H, Tuchnitz A, et al. Transthoracic detection of regional myocardial perfusion abnormalities using a pervenous contrast agent-a comparative study of Doppler energy and grey scale imaging [abstract]. $\mathrm{Br}$ Heart F 1995;73(suppl 3):P57.

60 von Bibra H, Tuchnitz A, Firschke C, et al. Doppler tissue imaging of left ventricular myocardium - initial results during pharmacological stress [abstract]. I Am Coll Cardiol 1995;25:P57A.

61 Nosir YFM, Fioretti PM, Vletter WB, et al. Accurate measurement of left ventricular ejection fraction by three-dimensional echocardiography. A comparison wit radionuclide angiography. Circulation 1996;94:460-6.

62 Salustri A, Becker A, van Herwenden L, et al. Threedimensional echocardiography of normal and pathologic mitral valve: a comparison with two-dimensional transoesophageal echocardiography. 7 Am Coll Cardiol 1996;27: 1502-10.

\section{Further reading}

Schiller NB, Foster E. Analysis of left ventricular systolic function. Heart 1996;75(suppl 2):17-26.

Yamamoto K, Redfield MM, Nishimura RA. Analysis of left ventricular diastolic function. Heart 1996;75(suppl 2):27-43. European Study Group on Diastolic Heart Failure. How to diagnose diastolic heart failure. Eur Heart $\mathcal{F}$ 1998;19:990-1003. Wranne B, Baumgartner H, Flachskampf F, et al. Stenotic lesions. Heart 1996;75(suppl 2):36-42.

Simpson IA, de Belder MA, Kenny A, et al, on behalf of the British Society of Echocardiography. How to quantitate valve regurgitation by echo Doppler techniques. Heart 1995;73(suppl 2): $1-9$ 